\title{
CHARITABLE LOVE: \\ BEARING THE OTHER'S TRANSCENDENCE
}

\section{PAUL MOYAERT}

KULeuven

\begin{abstract}
According to a popular view charity is reduced to mercy and benevolence. Through an exploration of traditional, Christian, charitable acts both corporeal and spiritual in nature - I set out to develop an alternative view. Why, for example, is the simple act of laying the dead to rest considered an act of charity? Feelings of pity and commiseration offer an insufficiently firm basis for justifying such an attribution. By adopting the burial of the dead as a sort of touchstone, I suggest that the (corporeally or spiritually) indigent other finds him- or herself in need of charity at the precise moment that he or she loses the ability to react as a person. Sometimes being charitable comes to expression in relinquishing one's demands that the other behave as morally responsible people ought to behave. Charity involves the question of how to bear the other's 'transcendence'.
\end{abstract}

In Upheavals of Thought: The Intelligence of Emotions (2001), Martha Nussbaum gives voice to a number of reflections on the nature and meaning of charity. ${ }^{1}$ Her account develops an understanding of charity, or compassionate love, in terms of clemency and mercy, or more to the point, from the viewpoint of a 'merciful judge': '[m]ercy is defined as the inclination of the judgment toward leniency in selecting penalties: the merciful judge will often choose a penalty milder than the one appointed in law for the offense' (p. 365). Ultimately, Nussbaum's focus on charity forms an important part of her moral-philosophical appeal for greater compassion, an appeal that she aims directly at the ethical theories of philosophers like Spinoza, who maintain that benevolence and humanity should be sought (and defined) independently of the emotional whims of compassion. Drawing from Seneca, she outlines

\footnotetext{
${ }^{1}$ Martha Nussbaum, Upheavals of Thoughts. The Intelligence of Emotions (Cambridge: Cambridge University Press, 2001).
} 
a total of three arguments in support of her idea that charity qua compassion is an expression of moral goodness. Firstly, she argues that mercy accords with an aristocratic and virile ideal of self-esteem. Instead of demanding an attitude of self-debasement and servility, it actively affirms one's power. It is thus anything but a sign of weakness or of a cringing unwillingness to cause pain to others. Secondly, she sees mercy and leniency as being rooted in a deeper understanding (or appreciation) of the flaws, vulnerabilities and failings of human beings. She even goes so far as to argue that a view of human nature which sees only beauty, goodness and strength in individuals betrays a certain shortsightedness and moral shallowness: "I'll love you only to the extent that you exemplify properties that I otherwise cherish.' This attitude has no room for mercy, for an embracing unconditionality in love seems well suited to a life of imperfection and vulnerability.' (p. 499) Just as compassion is willing and able to accept the other's failings, shortcomings and so forth, so a lack of such compassion is clearly at odds with true love. Thirdly, Nussbaum argues that compassion both nourishes and undergirds the shared life of human communities. Insofar as it spares the other from being cast out or barred from communal life, it actively restores relationships between friends and neighbours, or between a child and his or her parents. What's more, it is even powerful enough to create new bonds of communal solidarity. In short, the more compassion is exercised by members of a community, the stronger the community grows. Indeed, Nussbaum even charges, somewhat more broadly, that communities are not shaped and maintained through duties and rights alone, for generosity also plays a key role in binding them together. While there may not be any possibility of exercising generosity apart from the law, it nevertheless opens up a communal space beyond the law. And while other members of your community may be able to evaluate and measure your acts of compassion and generosity, there is no way for them to lay any blame at your feet for lacking in it.

In the following remarks, I would like to focus in particular on two claims that Nussbaum advances: that compassion ought to be viewed as a form of clemency or leniency, and that its principal source of value derives from its dual-capacity both to foster and restore communal life. By and large, I imagine it's safe to assume that few will be tempted to challenge these claims. In what follows, however, I shall argue that the mindset of the clement judge, on the one hand, and the wellbeing of the community, on the other, fall short of offering a robust view of charity. As 
I hope to show, clemency fails to give full expression to what's ultimately at stake in acts of charity, and while discussion of a close relationship between compassion and communal life may be superficially correct in certain instances, it remains fundamentally misleading in others. Please don't misunderstand my larger aim here: charity is undoubtedly a form of altruism - I am not interested in disputing this point, nor in advancing a completely different view. What I would like to challenge, however, is Nussbaum's view that this particular form of altruism necessarily works for the greater benefit of the community. As I would like to argue, any effects on the life of the community are secondary in nature.

In order to set up the following discussion and frame a richer and more comprehensive picture of charitable love, I would like to draw from what Christian theologians and philosophers have long referred to as the fourteen acts of charity, which can be found in Thomas Aquinas' Summa Theologiae 2a 2ae, quaestio 32, art. 2. The specific term Thomas employs here is eleemosynae, ${ }^{2}$ and he divvies each of the fourteen deeds up into two separate categories. Under the heading of physical deeds of charity, firstly, he includes offering nourishment to the hungry, giving drink to those who thirst, clothing the naked, providing refuge to the foreigner, visiting the sick at their bedside and prisoners in their cells and, finally, burying the dead. Next, the spiritual acts of charity include instructing the ignorant, offering counsel to those in doubt, providing consolation to the afflicted and those in mourning, admonishing the wayward sinner, bearing with those who are burdensome or troublesome with patience and longsuffering, forgiving your enemies and praying for everyone, whether living or dead. While these lists may not offer an explanation of what charity effectively consists in, they do provide us with a number of helpful examples of how compassionate people act in certain circumstances.

In Christian spirituality, these fourteen acts of charity are also meant to serve as a practical illustration of how the command to love one's neighbour as oneself ought to be understood and put into action. It is of course a well-known fact that this command is far from being unique to the Christian tradition. In addition to figuring explicitly in the Old Testament, it also features prominently in a number of other major spiritual traditions. The one thing that marks Christian neighbourly

${ }^{2}$ Lexikon für Theologie und Kirche, Bd. X, kol. 1052-1054, <Werke der Barmherzigkeit> (Freiburg i. B.: Herder, 1965). 
love as unique and rather peculiar - indeed, the one thing that brings it closest to utter anarchy - is the extension of the command to cover love of one's enemies. This is undoubtedly far and away the most contranatural demand ever placed on human shoulders - a demand utterly bereft of any conceivable natural foundation. Traditionally, naturalistic conceptions of moral sensibility have viewed pleasure and pain as precursors, or natural templates, of good and evil. In addition to offering natural expressions of good and bad, they also serve as trusty guides for one to follow. Insofar as our bodies love what is good and hate what is bad or harmful, pain and pleasure figure as spontaneous, bodily expressions of love and hate. To follow the command to love my enemy as myself demands that I embrace someone who makes me suffer or violates something I cherish. It flies directly in the face of my natural inclinations and is totally impossible to respect, as a command, without first redirecting my aggression, naturally targeted at my enemy, against myself. Adherents and disciples of Christianity are perfectly aware of the command's disturbing character. They do not fail to see it as a stumbling block, or as a kind of moral insanity, that directly conflicts with the ideals of fairness and justice. Criminals ought to suffer punishment they do not merit love, and particularly not the love of those they harm and violate. Indeed, Nietzsche and Freud were both clearly justified in claiming that, with this command, Christianity planted a bitter seed of infinite guilt directly into the beating heart of our moral sensibility. It is utterly impossible to understand - let alone heed - this command without a keen awareness of its disturbing, unnatural cruelty. Whatever I may do, or however I may react to the wrongdoing of my enemy, it is never enough. And if I fail to do more than I did, the blame rests entirely on my shoulders, for the command forbids nothing.

The first thing to take note of in Thomas' list of charitable deeds is that it does not answer (let alone raise) the question of who my neighbour is. Nowhere is the neighbour identified as a friend or family member, for example; nor does Thomas' list single 'the neighbour' out as a member of a given race or nation, or as someone who shares my beliefs. Indeed, no social relation whatsoever is offered as a point of reference capable of determining who may (or may not) be my neighbour. Instead, the list seems to define my neighbour quite simply as he or she to whom I show compassion, toward whom I act in a neighbourly way. In other words, I am the neighbour of him or her to whom I show mercy - not the other way around. In the parable of the Good Samaritan, for instance, 
we see this reversal of perspective brought quite plainly to the fore. After recounting the parable, Christ asks his listeners: 'Which of the three was, according to you, the neighbour of the victim of the robbers?' (Luke $10: 36)$

With this in mind, let's take another look at the double list. What the list makes immediately clear is that the paradigm of the clement judge is far too weak to fully grasp what's at stake in charitable love. Take for example the burial of the dead: how could the act of laying the dead to rest possibly be viewed as a form of clemency or leniency? If I single out this charitable deed in particular, it is not without reason, for the peculiar status of the other's lifeless corpse helps to give a clearer and much more vivid idea of the ontological condition of him or her who, as a living human being in need, makes a claim on my charity. Both the living person in need of my love and the still, cold corpse are situated in the same ambiguous space of an ontological 'in-between' - they are, at one and the same time, both inside and outside the field of communal, social life. Taking the burial of the dead as a paradigm helps us to clarify why acts of charity cannot be defined uniquely in terms of their positive social impact. On my view, the core of charitable love is to be found, not in mere clemency, but in patience and longsuffering. What charity bears with, or suffers, is precisely the community's powerlessness to fully restore itself, or to mend the tear that ruptures it internally. It steadfastly occupies the gap that tears the community's social fabric from within; it accepts the fact that the wound, or gap, between myself and my neighbour, cannot be healed. Later on, in the second part of my paper, I will elaborate on this view in greater detail. Afterwards, in the conclusion, I will then discuss the sense in which patience, or longsuffering, gives shape to the spiritual dimension of charitable love.

Firstly, however, we have a pressing question to respond to: how is the act of laying a dead body to rest so helpful in illustrating what's going on in charitable love?

\section{BURYING THE DEAD: A CHARITABLE DEED?}

It should be relatively obvious why this particular act of charity fails to chime with Nussbaum's view as outlined above: neither leniency nor compassion play any role in motivating the act of laying the dead to rest. It is particularly instructive for us as philosophers insofar it undermines our frequent inclination to reduce altruism to a form of benevolence, 
to a reduction of pain and suffering, or to assisting those in need. The other's lifeless body doesn't need my help at all; in contrast to someone in need, it doesn't suffer anything whatsoever. From a certain point of view, of course, you could make the argument that the act of laying the dead to rest can be re-inscribed in a broader altruistic framework, or in a more comprehensive, derivative need. For example, you could point out that giving the body a proper burial helps assuage the grief of surviving friends and family members. This line of argument isn't entirely convincing, however, for it clearly begs the question of what you were doing in 'helping' the corpse as such.

The act of burying the dead is not the only charitable deed that compels us to rethink our common understanding of charity as a form of benevolence, assistance or reduction of the other's suffering. Suffering, of course, can take at least two different forms: physical suffering and mental suffering. If we revisit Thomas' list of the spiritual deeds of charity, we stumble across a number of charitable acts that have little if anything to do with diminishing mental suffering, or providing spiritual assistance. Indeed, suffering doesn't even seem to enter the picture in some of the spiritual, charitable acts. Take the example of patiently tolerating the annoying and troublesome aspects of a person's behaviour (or character). People with obnoxious habits and character flaws don't necessarily suffer, themselves, from these flaws - on the contrary, it's his or her friends and family who do all the suffering! Or take the example of praying for others. Charitably praying for others, as their neighbour, is a fundamentally symbolic act, which cannot be measured up in terms of its efficacy in helping (or failing to help) those in need. ${ }^{3}$

While these sorts of observations might tempt us to try to rethink charity completely independently from our usual notions of aid and compassion, what I would simply like to draw attention to is how they force us to reconsider the deeper significance of helping those in need, or ministering to the other's suffering. The willingness to help others (or actually helping them) is commonly associated with an attitude of subordination and servitude: someone who helps others makes him- or herself subservient to them, which requires an attitude of respect, awe or reverence.

\footnotetext{
${ }^{3}$ Arnold Burms, 'Moral Taboos and the Narrow Conception of Morality', in A. W. Musschenga (Ed.), Does Religion Matter Morally? (Kampen: Kok Pharos, 1995), pp. 95-107.
} 
This is precisely what we find going on in the act of burying the dead, or indeed in any act of charitable service: burial honours the deceased and pays respect to them. Rather than 'meeting the needs' of the deceased, which is of course quite meaningless, I pay my respects to his or her dignity as a fellow human being.

Honouring someone, whether living or dead, requires that I recognize the special place that he or she occupies in the world. What this involves is a fundamental affirmation, taken to the extreme, of the basic, ontological difference between man and other living (or non-living) beings, such as plants, animals and brute matter: I affirm and resolutely insist upon this difference out of respect, even and especially when it risks being effaced or when I have trouble discerning it, such as when someone passes away. In the moments immediately following a person's death, their face may still be clearly recognizable, but it doesn't take long before it finally breaks apart - at which point the difference between man and lifeless matter (or daisy-fodder) ultimately gives way. It is precisely in these moments when nature's indifference cruelly reasserts itself, however, that we re-inscribe this difference by means of a symbolic gesture, such as burying the dead. By covering the body with a white sheet, cremating it or laying it to rest deep in the earth, we re-affirm the difference between man and other natural beings. In this way, we guard the human body from anything that threatens to nullify its fundamental dignity. In a very real sense, we hold the deceased back from dissolving into nothingness, protecting him or her from the impersonal, natural forces that threaten to obliterate his or her unique place in the world. By 'paying respect' to the deceased's body, I do something for it that it's powerless to do for itself: I honour and dignify it at the very moment when it loses hold of its human dignity. While this is quite clear in the case of burying the dead, couldn't we also recognize the same fundamental intention, or the same respectful appreciation of the other's dignity, in clothing the naked and other charitable deeds? Even while clothing the naked may serve the vital interests of sheltering the body from the elements and physical harm, at a deeper level, it is also a way of taking the body's dignity into protection. In a similar way, the other physical deeds of charity (such as feeding the hungry and giving drink to the thirsty) not only meet the needs of the body but restore and reaffirm its dignity in the face of nature's impersonal forces. Ultimately, this is the aim of the service involved in acts of charitable love: restoring the dignity of those suffering under inhuman and degrading circumstances. On a superficial level, of course, 
charity may (in some cases) serve to alleviate the other's suffering, but the underlying metaphysical motivation is clear: to restore human dignity. If we strive to diminish other people's suffering, it is ultimately because the suffering gnaws away at their dignity. This, as I would argue, is where Nussbaum's account falls short: in focusing exclusively on benevolence and acts of leniency, it fails to seize hold of the deeper motive force driving the exercise of charitable acts.

In a phenomenological perspective, the corpse bears the ambiguous status of an ontological 'in-between', as Gorgio Agamben would put it. ${ }^{4}$ Though it is definitively cut off from life, it doesn't automatically reduce to the level of brute, lifeless matter either. It still bears the form and appearance of the living being that it was when alive, and yet it no longer has a place in the world of the living. And while it no longer shares in the sphere of human meanings and values, this doesn't mean that it's simply cast out of that sphere either. On Freud's view, the corpse belongs to the field of the uncanny as a presence without a proper place: though it clearly isn't 'here in our midst' in the same way that we are present 'in the midst' of other, living people, it isn't simply 'gone' or 'absent' like a student is absent from class. Marked by an unsettling excess that is impossible simply to tuck away somewhere, hidden from view, it falls both inside and outside our world. The act of laying the body to rest out of charitable love is a recognition of the peculiar ontological position it occupies with respect to the community of the living.

We can gain an insight into the human condition by more closely examining this peculiar ontological position occupied by the human corpse. But what insight is that, exactly? Human beings straddle two different worlds at one and the same time. While we belong to a world shared in common with other, fellow human beings, as individual men and women, part of us, of necessity, falls outside the scope of what we hold in common. We are thus members of a larger social body and beings without full membership to that body. As individuals, we are beings without a proper home, without a horizon of shared meaning held in common with each other - hence the sense of desolation and isolation we feel even as we live our lives in common with other members of a larger social body. A radical sense of isolation is inherent in our very existence, an isolation that social interaction, communication or the

${ }^{4}$ Giorgio Agamben, Homo Sacer: Sovereign Power And Bare Life (1942) (Stanford, California: Stanford University Press, 1998). 
care of others can never completely eradicate. Complete 'socialization', or full membership in the social group, is simply not an option. This, as I would argue, is precisely what the radical loneliness of a dead body reminds us of. What it brings so forcefully to the light is the awkward, 'in-between' position that we occupy as socialized human beings, this position both in and outside the social world, which, in our daily lives and interactions with others, we are so quick to lose sight of. The account we find Nussbaum advancing fails to understand charitable love within this larger ontological perspective on the human condition.

In our daily lives, the deeper, metaphysical insight I have outlined above most often remains lurking somewhere in the background. In the rare moment that it comes to light in our experience, it vanishes just as quickly as it appears. When someone calls out to us and makes an appeal on our charity, it is ultimately this feature of our human condition - not a mere need or want - that forcefully imposes itself on us. My neighbour or rather, the one whom $I$ am called to love as a neighbour - beckons to me from somewhere 'beyond' the shared space of the social body. The other's appeal on my charity confronts me, not simply with a fellow human in need of my help, but with the abject and pathetic loneliness of his or her condition as a human being. Allow me to be clear: there isn't any need for us to understand this 'beyond' as some sort of hidden reality tucked away behind the familiar façade of social life. On the contrary, all I understand by this 'beyond' is the pure and simple impossibility of being wholly inscribed within the shared space of the social body. Part of who we are, as humans, simply does not - and cannot - belong. With this, we've found our way back to the theme I highlighted earlier on, namely of patience or longsuffering, or of what I am referring to as the radical core of charitable love.

\section{SPIRITUAL ACTS OF CHARITY: BETWEEN ACTS OF LOVE AND LOVING INACTION}

Charity is frequently thought to extend ordinary forms of loving social interaction beyond their usual scope, or as an expansion upon what we already find ourselves doing for others. But how exactly should we understand this extending, broadening movement? Taken at face value, it would seem to imply a simple expansion of the social field where we usually act out of love and compassion. What we already do without 
a second thought for friends and members of our family, we do for those who stand at a greater remove from these more intimate social circles. In other words, according to this view, charity consists in loving action carried out for humanity as a whole. Of course, this clearly assumes that the love involved in our more intimate social relations - love for our children or elderly parents, for instance - are themselves already charitable in nature. In other words, on this view, there isn't any essential difference between charitable love and the spontaneous compassion we already show to those we hold dear in some measure or another. Indeed, the story of the Good Samaritan is frequently interpreted in precisely these terms: what we need to do, as charitable neighbours, is to extend our kindness and compassion to those standing outside our community.

While there's little doubt that we ought to act charitably toward those who don't happen to fit within our social circle, the simple notion of expanding the scope of our altruism fails to clarify much of anything as far as charity is concerned. But why not? What it mistakenly leads us to assume is that our relations to friends and family members are themselves already charitable in nature. In other words, it fails to take into account the highly specified circumstances in which others make an appeal to our charity. Rather than understanding charity as a simple extension of loving, social relations, what we need to seize hold of is how it completely suspends and transforms existing social relations, however fleeting or temporary this suspension may be.

In order to more firmly hammer this point out, allow me to establish a distinction between two different ways of understanding personhood, one metaphysical in nature, the other practical. The metaphysical conception of personhood, which Kant and Gaita define in terms of sanctity, bears upon the dignity that a person holds irrespective of his or her qualities or capacities as an individual or of the social group to which he or she happens to belong. ${ }^{5}$ Simply put, the basic ontological fact that one is a member of the human species means that one bears an indelible and inalienable dignity as a person. On the other hand, the practical conception of personhood concerns one's capacity to participate in the field of human values and meanings in appropriate ways, that is, in the ways that people are expected and supposed to participate. While someone with a major disability may no longer be able to make conscious, deliberate

${ }^{5}$ Raimond Gaita, A Common Humanity. Thinking about Love and Truth and Justice (London \& New York: Routledge, 2002). 
decisions or act as a 'person' normally would in certain circumstances, she nevertheless retains her personhood in the metaphysical sense of the term. Even though she lacks the practical capacity to act or to determine the course her life will take, this doesn't deprive her of her dignity, or sanctity, as a person. Ultimately, what I'm trying to get at here with this practical conception of personhood relates to what Strawson has in mind when he speaks of 'reactive attitudes' in Freedom and Resentment. ${ }^{6}$ What Strawson understands by reactive attitudes is a set of capacities allowing one to take responsibility for one's actions, or more broadly, a sensitivity to and understanding of the complex interplay involved in the motivations and intentions that give shape to human behaviour. A 'person' in the practical sense of the term is someone who, quite simply, cares how others view and judge her behaviour, who is capable of feeling pride and shame, who grasps the practical significance of guilt, repentance, responsibility, forgiveness and so forth. In the end, it proves rather difficult (and beyond the scope of this essay) to frame a definition of reactive attitudes that is both precise and globally comprehensive, for practical notions of personhood vary significantly over the course of history and from culture to culture. For the purposes of the present study, all we need to draw from the practical conception of personhood is, firstly, this notion of a sensitivity to practical motivations and moral values and, secondly, the idea that it provides the moral basis of personal responsibility.

In order to better clarify what's at stake with the practical understanding of personhood, consider the following, simple examples. When I offer help to someone in need, I am not overstepping my bounds when I expect him or her to express a certain measure of gratitude to me. Expectations of this sort are given shape to a large extent in the process of socialization, such as when a child is taught to say 'thank you' even for a disappointing birthday gift. Similarly, when people find themselves afflicted with adversity, they are encouraged to bear their hardship with at least a modicum of dignity. If I erupt in a childish tantrum when things don't go my way, I am rightly blamed for behaving inappropriately. People expect me to understand that my outburst lacked the necessary decorum, or that certain excuses fall short of justifying my reaction, even though they may have been appropriate in other circumstances. The basic assumption undergirding these sorts of practical considerations

${ }^{6}$ P. F. Strawson, Freedom and Resentment and Other Essays (London: Methuen, 1974). 
is that people generally pay heed to how others view and judge their behaviour.

To my mind, charity can only truly be practiced for people who, for one reason or another, no longer have the capacity to react appropriately, or who can no longer fully take part in the shared, interpersonal space of human values and meanings. Instead of starting out from the question of who my neighbour is, the question we first need to be asking is this: under what conditions or circumstances does someone become an object of pity for me? If my normal way of behaving and relating to people is conditioned by certain assumptions about their practical motivations and expectations, what sort of circumstances need to come into play for a person to make an appeal (either expressly or implicitly) to my charity? As I would like to argue, charity only really enters the picture when the set of reactive attitudes that normally govern human interactions is significantly altered in some way or another. In other words, charity consists much less in an expansion of my normal attitude than in its radical suspension, however temporary or fleeting: rather than broadening my spontaneous expressions of altruistic behaviour, charity radically transforms and modifies my altruism.

The reader will likely have little difficulty seeing how this view of charity falls right in line with our earlier discussion of burying the dead, for while the deceased individual clearly lacks any practical capacity to behave in any way whatsoever, he or she undoubtedly remains a 'person' in the deeper, metaphysical sense of the term. Precisely insofar as he or she falls, at one and the same time, both within and beyond the scope of everyday, interpersonal interactions, the deceased becomes an object of my charitable love. What this example makes clear, in other words, is how acts of charity are ultimately grounded in the insight that the practical understanding of personhood has at least temporarily lost its grip on him or her who stands in need of my loving care. As long as he or she continues to take part in the sphere of human meanings, values and practical motivations, charity cannot and need not enter the picture. Only when someone's misery, poverty or disability disengages her from the sphere of common, interpersonal, reactive attitudes, is my neighbourly, charitable love really at stake. The crux of the charitable attitude is precisely to bear with this crippling poverty and incapacity, just as Christ bore with the stubborn ignorance of those who cruelly cried out for his crucifixion: 'Father, forgive them for they don't know what they are doing' (Luke 23:34). 
We are mistaken when we see charity necessitating a limitation on our egoism, for what needs to be limited above all else is much less our egoism than the reactive attitudes that inform and give shape to our social relations. When I carry out an apparently charitable deed and refuse to hold myself back from exhorting the other to react in an 'appropriate' way, or as people normally would react, I nullify my charitable love with cruelty. Why do we find it so challenging to put these inclinations to exhort and morally admonish the other in check? Quite simply, because they give shape to what it means to be a 'person' in the practical sense of the term. With charity, in contrast, I have to learn to move and behave somewhere 'in between' the expectations that I usually place on the other's behaviour and the temporary suspension, or neutralization, of these expectations.

The understanding of charity as a temporary bracketing of our reactive, interpersonal attitudes clearly chimes with the exercise of patience or longsuffering. Charitable love is a fundamentally patient love, a love that bears with the other's transcendence as a person. (With this definition, I'm drawing directly from the passage from Paul's first letter to Corinth (1 Cor. 13:4) where he writes that love is patient and kind, not boastful or arrogant.) One importance consequence of defining charity in this way is that actions like consoling those in distress, instructing the ignorant or counselling those in doubt cannot, in and of themselves, be counted as acts of charity. Indeed, these are actions that we already perform for our friends, equals and those close to us without a second's thought; they make up some of the basic modes of conduct through which we interact with each other as persons (in the practical sense of the term). How is it, then, that these sorts of altruistic actions can be made to transform into acts of charity? Allow me to present a few, simple examples to help clarify my point of view.

Counselling those in doubt only becomes a charitable act when the person in doubt finds herself mired in indecision, or when, in spite of being open to my advice, she feels herself powerless to pay any heed to it at all. As someone seeking and demanding the counsel of others, she clearly takes part in normal, interpersonal relations, but, at the same time, she is also broken off from these relations insofar as my advice cannot but 'fall on deaf ears', as we say. By virtue of this indecisiveness and impermeability to my advice, the person becomes an object of my charity. In this case, then, we find that charity consists in a willingness 
to lovingly bear with the other's incapacitating lack of resolution and 'deafness'.

In a similar way, consoling those in distress (or 'mourning with those who mourn') becomes a charitable deed in the precise moment when the person in distress becomes numb to the commiseration of others. Instead of expecting my consoling words to assuage the other's grief, I act as a loving neighbour when I recognize my powerlessness to make a dent in her radical inconsolability.

Consider next the example of forgiveness. Without any further qualifications, I would be remiss to see forgiving the offenses of others as an act of charitable love in and of itself. If, for example, I forgive someone who has already shown regret for offending or harming me in some way, then my forgiveness is much less an act of charity than a normal 'reactive' response to her admission of wrongdoing. Indeed, to admit one's failings and to forgive the failings of others are essential components of our spontaneous moral attitude. It is only when I patiently bear with an offense or insult as such, without any expectations of reciprocity, that I act charitably towards my neighbour. On this point, my view undoubtedly diverges to a certain extent from that of the Christian tradition, for as I am arguing, charity does not require a willingness to pardon ever-greater offenses. To my mind, charity has much less to do with continually turning the other cheek, or forgiving the unforgivable, than with the recognition of our powerlessness to forgive all wrongs. In other words, rather than seeing forgiveness as an omnipotent balm capable of healing every wound, or of standing in the breach of every rupture in the community, a charitable approach to wrongdoing and injury patiently suffers with wrongs that cannot be righted. If anything, true charity requires that we swallow the hard and bitter fact that the community cannot fully rid itself of division and strife, that it cannot heal all its wounds or pardon every wrong.

In extreme circumstances - that is, in circumstances demanding something beyond our usual reactive attitudes - we find ourselves compelled to accept our radical powerlessness to change anything whatsoever about the other's 'in-between' situation. Here we meet up with a fundamental limit to the powers of our compassion and benevolence, a limit just beyond which the charitable dimension of certain actions (such as forgiveness) comes to light in the impotence that properly defines them. Even while these sorts of circumstances may be quite rare 
and extraordinary, they are particularly helpful in reflecting on what's ultimately at stake in charitable love.

What is charity effectively capable of in such extreme circumstances? By this point, the answer should be relatively clear: all that it has the power to do is patiently bear with the fact that nothing - not even forgiveness - can help change things. In the contemporary world, charity is most often associated with gifts of money, time and resources to people in need, such as when aid workers are sent off to help those in countries ravaged by natural disasters and war. What this common understanding of charity makes possible is a handy (and morally comforting) measure of beneficent, compassionate action: the greater the reduction in emotional suffering and/or physical distress, the greater the power of the charitable deed. It is considerably more challenging to understand charity in instances where assistance proves to be powerless, or when there is no longer any way to measure the concrete, moral 'profit' of the charitable action. This nevertheless begs a pressing question: is there not, in charity, something more involved than the practice of longsuffering patience, something beyond the mere, resigned acceptance of charity's powerlessness to alter an irremediable situation? Is it really the case, to borrow a famous expression of Jacques Lacan's, that love is nothing more than 'a giving of what one doesn't have'?

From a secular viewpoint that directly equates charity and aid, the exercise of patience and longsuffering is liable to appear as the only possible recourse to irremediable suffering. Another perspective opens up, however, if we pause to reflect on prayer as a form of charitable action, a perspective that fails to come into view when charity is addressed exclusively in moral and ethical terms. A brief exploration of the nature of prayer should help us see how more is involved in charity than the tragic necessity of bearing with one's powerlessness to help those in need.

\section{PRAYER AS AN ACT OF CHARITY}

Reflection on prayer allows us to highlight charity's metaphysical and spiritual core. In our daily lives and social interactions, we spontaneously work from the assumption that those we relate to in the world around us are open to the good, or animated by a yearning for wellbeing and wholeness. Similarly, we hold each other accountable for our actions as a matter of course, or as if it were second nature. We cannot hold ourselves back from praising and blaming the actions of others (let alone 
our own actions) without running into conflict with our most basic, moral inclinations and habits of thought. Attitudes concerning guilt and personal responsibility are at the very core of our moral sensibility indeed, without them, we have no way to understand what it even means to be a moral agent. For the most part, we don't pay any mind to this basic, a priori structure of our existence as moral creatures.

It is only in certain circumstances, when we come across someone who is no longer able to share in this basic, moral attitude, that we become aware of it as a background assumption responsible for giving shape to our moral lives. These circumstances are certainly not unfamiliar to us: when my neighbour grows distressingly numb to feelings of shame and pride, when my well-meaning advice falls on deaf ears, or when, to borrow an expression of Kierkegaard's, my words of consolation fail to penetrate the 'inclosing reserve' of my neighbour's misery, my reactive attitudes suddenly lose their grip on the social relation binding me to my neighbour. In situations like these, we instinctively try to determine who it is that bears responsibility for the ruptured relation, or for the practical, moral failure. Who is to blame? Are my efforts simply not enough, or is the person I'm trying to help at fault in some way? As if by a sort of knee-jerk reaction, we not only struggle to determine who is responsible for what but what it is that could be done to overcome the apparent limitation on the powers of the good. Unfortunately, answers and helpful solutions are exceedingly difficult to come by in situations like these. Either we hold the other responsible for closing herself off from the good, and if need be, we admonish her to be more receptive to (and grateful for) our attempts to help. Or we blame ourselves for failing to be more forgiving or more compassionate. Ultimately, it's hard to swallow the fact that neither party bears responsibility. The immense staying power of our reactive attitudes doesn't allow us to abandon this tendency so easily, and as a result, we continually vacillate between laying the blame at our own feet, in which case we often compel ourselves to make even greater efforts, or we pass the lion's share of the guilt onto the other's shoulders and simply walk away.

We experience something of a moral shock when we bump up against these sorts of limits to helpful, benevolent action - or more broadly, to

${ }^{7}$ Soren Kierkegaard, The Concept of Anxiety: A Simple Psychologically Orienting Deliberation on the Dogmatic Issue of Hereditary Sin (Princeton, New Jersey: Princeton University Press, 1980), p. 124. 
the powers of the good. It is indeed a rather jarring discovery to find that goodness and well-meaning gestures have painfully definite limits. In encountering these limits, a fierce resistance from a moral attitude, which suddenly and inexplicably finds itself to be inoperative, cannot but bubble up to the surface. This violent resistance is part and parcel of ethics as such; it is a sort of unyielding, powerless rage that struggles against the limited powers of the good. Charity exhorts us to set this violence to rest and to adopt a seemingly impracticable attitude of patient longsuffering, an attitude situated uncomfortably in the no-man's-land between action and inaction, or between activity and passivity. In other words, we could say that charity radically neutralizes an essential aspect of our moral sensibility, or again, that it compels us to move beyond the basic assumptions, attitudes and categories that give shape our moral lives. Longsuffering patience occupies a space situated somewhere in between action and passion. Insofar as it struggles against the limits to the powers of the good, it fails to reduce to the level of mere indifference; and yet, at the same time, it also holds itself back from the violence that seeks to break through these limits. When our moral categories break down or fail to apply in the usual ways, what the charitable attitude brings to light is another who is both responsible and irresponsible. By putting ethics in suspension, charity proves itself to be more generous, lenient and liberal than ethics. And yet, at the same time, it also shows itself to be more cruel and demanding than ethics, for the patience it requires is ultimately grounded in an unsettling insight into the limitations of the good.

When charity exhorts us to neutralize and transcend the spontaneous inclinations of our moral sensibility, what exactly is there left for us to do? How are we to know what actions to take when our basic moral categories can no longer guide us? Do our moral practices teach us what we need/ought to do when we bump up against a radical limitation to moral action? Allow me to rephrase the question in different terms: while we have all been taught to forgive those who do us harm and to offer help to the needy, how are we to know what to do in situations when compassion is powerless to help and forgiveness fails to reconcile? Should we further bolster the strength and determination of our will (or blame the other when our renewed efforts come to grief)? Or should we rather abandon our charitable intentions/actions altogether and resign ourselves to our powerlessness? Are these really the only options left open: either to swallow a bitter pill and give up, or to persevere out of sheer tenacity? 
The teaching of spirituality offers us a way out of this abortive alternative, namely prayer. Praying for others is an especially important form of charitable love, particularly insofar as the longsuffering patience that it demands is concerned. First and foremost, it allows us to come to terms with our powerlessness to help those in need, for it is precisely at the moment when there is no further recourse left open that we turn to prayer. Though ethics is silent when it comes to situations in which our benevolence, pity and forgiveness run up against a dead-end, prayer opens up a way to move forward - or the very least, it allows us to remain engaged in a situation that falls entirely outside our control. With prayer, we seek the help that we ourselves, as finite beings, are no longer able to offer - a help that must come from somewhere else, namely from God's own charitable love. Recognizing the insurmountability of our limitations, we pray for God to help those whom we ourselves are incapable of helping. Prayer therefore clearly involves something more than patiently bearing with the other's transcendence, for it brings us to act at the very moment when morally inspired action is no longer even a viable option. In the spiritual exercise of longsuffering patience, which charitable acts like prayer carry out, the three, foundational, Christian virtues - faith, love and inexhaustible hope - draw together and interlock. 